\title{
Increasing the Number of Classifiers in Multi-classifier Systems: A Complementarity-Based Analysis
}

\author{
L. Bovino ${ }^{2}$, G. Dimauro ${ }^{1}$, S. Impedovo ${ }^{1}$, G. Pirlo ${ }^{1}$, and A. Salzo ${ }^{2}$ \\ ${ }^{1}$ Dipartimento di Informatica, Università degli Studi di Bari \\ Via Orabona 4, 70126 Bari-Italy \\ impedovo@di.uniba.it \\ ${ }^{2}$ Consorzio Interuniversitario Nazionale per l'Informatica (CINI), \\ Via G.Petroni 15/F.1, 70124 Bari- Italy
}

\begin{abstract}
Complementarity among classifiers is a crucial aspect in classifier combination. A combined classifier is significantly superior to the individual classifiers only if they strongly complement each other. In this paper a complementarity-based analysis of sets of classifier is proposed for investigating the behaviour of multi-classifier systems, as new classifiers are added to the set. The experimental results confirm the theoretical evidence and allow the prediction of the performance of a multi-classifier system, as the number of classifiers increases.
\end{abstract}

\section{Introduction}

Complementarity among classifiers is crucial in classifier combination. In fact, classifier combination significantly outperforms individual classifiers only if they are largely complementary each other. Complementarity among classifiers can be achieved by using different feature sets and classification strategies [1,2]. Alternatively, complementarity is also expected when different training sets and resampling strategies are used $[3,4,5,6]$.

In this paper a complementarity-based analysis of sets of classifier is used for investigating the behaviour of multi-classifier systems, as new classifiers are added to the set. The result allows the prediction of the effect of increasing the number of classifiers on the performance of multi-classifier systems. The experimental tests, which have been carried out in the field of hand-written numeral recognition, confirm the expected performance of the combination method and validate the proposed approach.

The paper is organised as follows: Section 2 introduces an estimator of complementarity for abstract-level classifiers. Section 3 shows the complementarity of a set of classifiers, as the number of classifiers increases. Section 4 presents the methodology used for the analysis of combination methods. The experimental results are discussed in Section 5. 


\section{Complementarity among Classifiers}

In order to measure the degree of complementarity among abstract-level classifiers, the Similarity Index has been recently introduced [7]. Let $A=\left\{A_{1}, A_{2}\right\}$ a set of two classifiers and $P=\left\{P_{t} \mid t=1,2, \ldots, N\right\}$ a set of patterns and let $A_{i}\left(P_{t}\right)$ be the class label produced by $A_{i}$ for the input pattern $P_{t}$. The Similarity Index $\rho_{A}$ for the set $\left\{A_{1}, A_{2}\right\}$ is defined as:

$$
\rho_{\left\{A_{1}, A_{2}\right\}}=\frac{1}{N} \sum_{t=1}^{N} Q\left(A_{1}\left(P_{t}\right), A_{2}\left(P_{t}\right)\right)
$$

and

$$
Q\left(A_{1}\left(\mathrm{P}_{\mathrm{t}}\right), A_{2}\left(\mathrm{P}_{\mathrm{t}}\right)\right)=\left\{\begin{array}{l}
1 \quad \text { if } \mathrm{A}_{1}\left(\mathrm{P}_{\mathrm{t}}\right)=\mathrm{A}_{2}\left(\mathrm{P}_{\mathrm{t}}\right) \\
0 \text { otherwise }
\end{array}\right.
$$

Of course, $\rho_{A} \in[0,1]$ : when $\rho_{A}$ is close to 0 , classifiers are strongly complementary; when $\rho_{A}$ is close to 1 , classifiers are weakly complementary. Figure 1 shows the outputs of two classifiers $A_{1}, A_{2}$, for $N=10$ input patterns $\mathrm{P}_{1}, \mathrm{P}_{2}, \ldots, \mathrm{P}_{10}$. Recognitions are indicated by $R$, substitutions by the labels $S 1, S 2, S 3$ (with $S i \neq S j, \forall i \neq j$ ). In this case the recognition rates for $A_{1}$ and $A_{2}$ are $R_{1}=0.7$ and $R_{2}=0.6$, respectively. The degree of complementarity between $A_{1}$ and $A_{2}$ is $\rho_{A_{1}, A_{2}}=0.6$. In fact:

- $\mathrm{P}_{1}, \mathrm{P}_{2}, \mathrm{P}_{3}, \mathrm{P}_{6}, \mathrm{P}_{7}$ are recognised by both classifiers $\left(\mathrm{Q}\left(\mathrm{A}_{1}\left(\mathrm{P}_{\mathrm{t}}\right), \mathrm{A}_{2}\left(\mathrm{P}_{\mathrm{t}}\right)\right)=1, \mathrm{t}=1,2,3,6,7\right)$;

- $\mathrm{P}_{4}$ is substituted by both classifiers which provide different responses: $A_{1}\left(P_{4}\right)=S 1$, $\mathrm{A}_{2}\left(\mathrm{P}_{4}\right)=53\left(\mathrm{Q}\left(\mathrm{A}_{1}\left(\mathrm{P}_{4}\right), \mathrm{A}_{2}\left(\mathrm{P}_{4}\right)\right)=0\right)$;

- $\mathrm{P}_{5}$ is substituted by both classifiers which provide the same response: $\mathrm{A}_{1}\left(\mathrm{P}_{5}\right)=\mathrm{A}_{2}\left(\mathrm{P}_{5}\right)=S 2\left(\mathrm{Q}\left(\mathrm{A}_{1}\left(\mathrm{P}_{5}\right), \mathrm{A}_{2}\left(\mathrm{P}_{5}\right)\right)=1\right)$;

- $\mathrm{P}_{8}$ and $\mathrm{P}_{10}$ are recognized by $\mathrm{A}_{1}$ and substituted by $\mathrm{A}_{2}: \mathrm{A}_{1}\left(\mathrm{P}_{8}\right)=\mathrm{R}$ and $\mathrm{A}_{2}\left(\mathrm{P}_{8}\right)=S 2$, $\mathrm{A}_{1}\left(\mathrm{P}_{10}\right)=R$ and $\mathrm{A}_{2}\left(\mathrm{P}_{10}\right)=S 1\left(\mathrm{Q}\left(\mathrm{A}_{1}\left(\mathrm{P}_{\mathrm{t}}\right), \mathrm{A}_{2}\left(\mathrm{P}_{\mathrm{t}}\right)\right)=0, \mathrm{t}=8,10\right)$;

- $\mathrm{P}_{9}$ is substituted by $\mathrm{A}_{1}$ and recognised by $\mathrm{A}_{2}: \quad \mathrm{A}_{1}\left(\mathrm{P}_{9}\right)=53, \quad \mathrm{~A}_{2}\left(\mathrm{P}_{9}\right)=\mathrm{R}$

\begin{tabular}{|c|c|c|}
\hline & $\mathrm{A}_{1}$ & $\mathrm{~A}_{2}$ \\
\hline Pattern 1 & $\mathrm{R}$ & $\mathrm{R}$ \\
\hline Pattern 2 & $\mathrm{R}$ & $\mathrm{R}$ \\
\hline Pattern 3 & $\overline{\mathrm{R}}$ & $\overline{\mathrm{R}}$ \\
\hline Pattern 4 & S1 & $\mathrm{S} 3$ \\
\hline Pattern 5 & S2 & S2 \\
\hline Pattern 6 & R & R R \\
\hline Pattern 7 & $\overline{\mathrm{R}}$ & R \\
\hline Pattern 8 & $\overline{\mathrm{R}}$ & 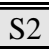 \\
\hline Pattern 9 & S3 & $\mathrm{R}$ \\
\hline Pattern 10 & PR & S1 \\
\hline
\end{tabular}
$\left(\mathrm{Q}\left(\mathrm{A}_{1}\left(\mathrm{P}_{9}\right), \mathrm{A}_{2}\left(\mathrm{P}_{9}\right)\right)=0\right)$.

Fig. 1. List of output of two classifiers 
In general, let $A=\left\{A_{i} \mid i=1,2, \ldots, K\right\}$ be a set of classifiers, $P=\left\{P_{t} \mid t=1,2, \ldots, N\right\}$ a set of patterns the Similarity Index $\rho_{\mathrm{A}}$ for the set $\mathrm{A}$ is defined as [7]:

$$
\rho_{A}=\frac{\sum_{\substack{\mathrm{j}=1, \ldots \mathrm{K} \\
i<j}} \rho_{\left\{A_{i}, A_{j}\right\}}}{\left(\begin{array}{c}
K \\
2
\end{array}\right)} .
$$

\section{Increasing the Number of Classifiers: Analysis of Complementarity}

Let $A=\left\{A_{i} \mid i=1,2, \ldots, K\right\}$ be a set of classifiers with Similarity Index equal to $\rho_{A}$, and suppose that a new classifier $\mathrm{A}_{\mathrm{K}+1}$ is added to the set. The Similarity Index of $A \cup\left\{\mathrm{A}_{\mathrm{K}+1}\right\}$ is (see eq. (3)):

$$
\begin{aligned}
& \rho_{A \cup\left\{\mathrm{A}_{\mathrm{K}+1}\right\}}=\frac{\sum_{\substack{i, j=1, \ldots K+1 \\
i<j}} \rho_{A_{i}, A_{j}}}{\left(\begin{array}{c}
K+1 \\
2
\end{array}\right)}=\frac{\sum_{\substack{i, j=1, \ldots K \\
i<j}} \rho_{A_{i}, A_{j}}+\sum_{i=1, \ldots K} \rho_{A_{i}, A_{K}+1}}{\left(\begin{array}{c}
K+1 \\
2
\end{array}\right)} \\
& \frac{\sum_{\substack{i, j=1, \ldots K \\
i<j}} \rho_{A_{i}, A}}{\left(\begin{array}{c}
K+1 \\
2
\end{array}\right)}+\frac{\sum_{i=1, \ldots K} \rho_{A_{i}, A_{K}+1}}{\left(\begin{array}{c}
K+1 \\
2
\end{array}\right)}=\frac{\sum_{\substack{i, j=1, \ldots K \\
i<j}} \rho_{A_{i}, A_{j}}}{\frac{(K+1)}{(K-1)}\left(\begin{array}{c}
K \\
2
\end{array}\right)}+\frac{\sum_{i=1, \ldots K} \rho_{A_{i}, A_{K}+1}}{\left(\begin{array}{c}
K+1 \\
2
\end{array}\right)} \\
& =\frac{(K-1)}{(K+1)} \frac{\sum_{\substack{i, j=1, \ldots K \\
i<j}} \rho_{A_{i}, A_{j}}}{\left(\begin{array}{c}
K \\
2
\end{array}\right)}+\frac{\sum_{i=1, \ldots K} \rho_{A_{i}, A_{K}+1}}{\frac{(K+1) K}{2}} .
\end{aligned}
$$

Hence:

$$
\rho_{A \cup\left\{A_{K+1}\right\}}=\frac{K-1}{K+1} \rho_{A}+\frac{2}{K(K+1)} \sum_{i=1, \ldots, K} \rho_{A_{i}, A_{K+1}}
$$

Of course, the variability of $\rho_{A} \cup\left\{A_{\mathrm{K}+1}\right\}$ depends on

$$
\sum_{i=1, \ldots, K} \rho_{A_{i}, A_{K+1}}
$$

In order to estimate to what extent the quantity (5) can vary, the relationships between $\rho_{A_{\mathrm{i}} A_{\mathrm{j}}}\left(\mathrm{A}_{\mathrm{i}}, \mathrm{A}_{\mathrm{j}} \in \mathrm{A}\right)$ and $\rho_{A_{\mathrm{i}} A_{\mathrm{K}+1}}, \rho_{\mathrm{A}_{\mathrm{j}} A_{\mathrm{K}+1}}$ (due to the extra classifier $\left.\mathrm{A}_{\mathrm{K}+1}\right)$ are determined in the following. For this purpose, from now on we suppose that all classifiers have similar performance, i.e. all of them have recognition rate equal to $\mathrm{R}$. 


\subsection{Analysis of the Complementarity between $A_{i}$ and $A_{j}$.}

Let $A_{i}$ and $A_{j}$ be two classifiers of $A$ with Similarity Index equal to $\rho_{\mathrm{A}_{\mathrm{i}} \mathrm{A}_{\mathrm{j}}}$ (Figure 2). The analysis of the outputs of $A_{i}$ and $A_{j}$ leads to the following cases:

$$
\begin{array}{ll}
\text { [A] } & A_{i}(t)=S i, A_{j}(t)=S j(S i=S j) ; \\
{[B]} & A_{i}(t)=S i, A_{j}(t)=S j(S i \neq S j) ; \\
{[C]} & A_{i}(t)=S i, A_{j}(t)=R ; \\
{[D]} & A_{i}(t)=R, A_{j}(t)=R ; \\
{[E]} & A_{i}(t)=R, A_{j}(t)=S j .
\end{array}
$$

Now, let $\mathrm{P}_{A}, \mathrm{P}_{\mathrm{B}}, \mathrm{P}_{\mathrm{C}}, \mathrm{P}_{\mathrm{D}}, \mathrm{P}_{\mathrm{E}}$ be the percentage of patterns corresponding to the cases $\mathrm{A}, \mathrm{B}, \mathrm{C}, \mathrm{D}, \mathrm{E}$ respectively, the following equations hold:

* $\mathrm{P}_{\mathrm{A}}+\mathrm{P}_{\mathrm{B}}+\mathrm{P}_{\mathrm{C}}+\mathrm{P}_{\mathrm{D}}+\mathrm{P}_{\mathrm{E}}=1$;

- $\mathrm{P}_{\mathrm{C}}+\mathrm{P}_{\mathrm{D}}=\mathrm{R}$ and $\mathrm{P}_{\mathrm{D}}+\mathrm{P}_{\mathrm{E}}=\mathrm{R}$

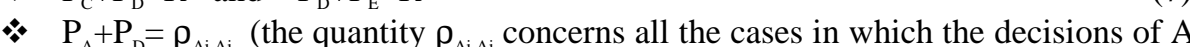
and $\mathrm{A}_{\mathrm{j}}$ agree, i.e. cases $(\mathrm{A})$ and $\left.(\mathrm{D})\right)$.

From eq. (8) it follows that:

$$
\begin{gathered}
\mathrm{P}_{\mathrm{A}}=\delta \\
\mathrm{P}_{\mathrm{D}}=\rho_{\mathrm{Ai}, \mathrm{Aj}}-\delta
\end{gathered}
$$

where $\delta$ is a positive quantity $\left(\delta<\rho_{\mathrm{Ai}, \mathrm{A}_{\mathrm{j}}}\right)$.

Moreover, from (7), (9) and (10), it results:

while from (6), (9), (10) and (11):

\begin{tabular}{|c|c|c|c|}
\hline $\mathrm{A}_{\mathrm{i}}$ & \multicolumn{2}{|c|}{$\mathrm{A}_{\mathrm{j}}$} & \\
\hline S1 & S1 & $\mathbf{A}$ & $\left(\mathrm{P}_{\mathrm{A}}=\delta\right)$ \\
\hline S2 & 53 & B & $\left(P_{B}=1-2 R+\rho_{A i, A j}-2 \delta\right)$ \\
\hline 53 & $R$ & C & $\left(\mathrm{P}_{\mathrm{C}}=\mathrm{R}-\left(\rho_{\mathrm{A}, \mathrm{A} \mathrm{A}}-\delta\right)\right)$ \\
\hline$R$ & $R$ & & \\
\hline$R$ & $R$ & & \\
\hline$R$ & $R$ & D & $\left(P_{D}=\rho_{A i, A i}-\delta\right)$ \\
\hline$R$ & $R$ & & \\
\hline$R$ & $R$ & & \\
\hline$R$ & $R$ & & \\
\hline$R$ & 52 & $\mathbf{E}$ & $\left(\mathrm{P}_{\mathrm{E}}=\mathrm{R}-\left(\rho_{\mathrm{Ai}, \mathrm{Aj}}-\delta\right)\right)$ \\
\hline
\end{tabular}

$$
\mathrm{P}_{\mathrm{C}}=\mathrm{P}_{\mathrm{E}}=\mathrm{R}-\mathrm{P}_{\mathrm{D}}=\mathrm{R}-\left(\rho_{\mathrm{Ai}, \mathrm{Aj}}-\delta\right),
$$

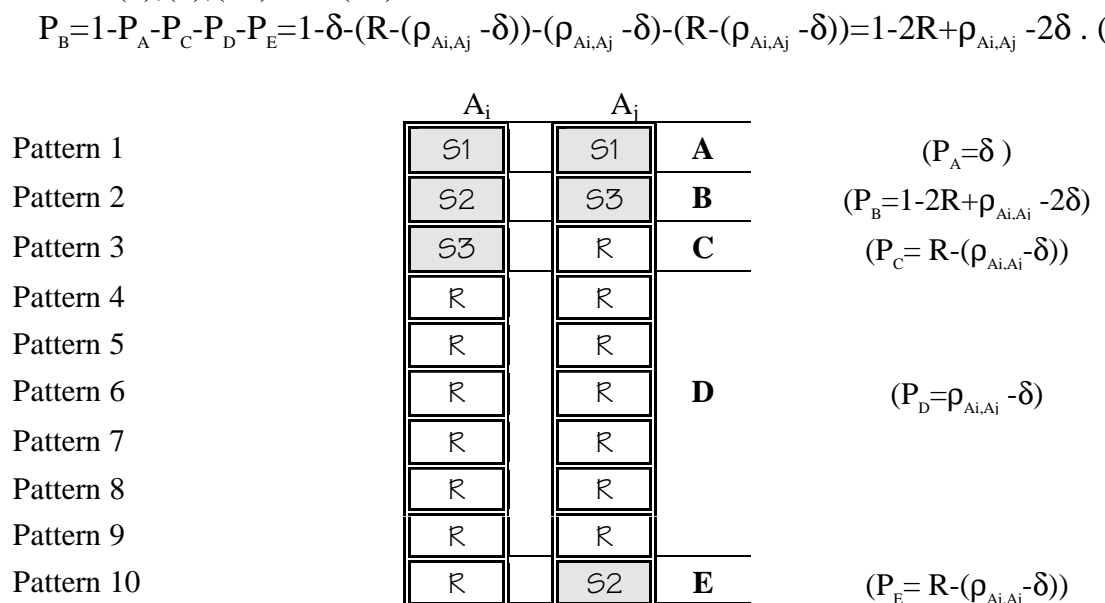

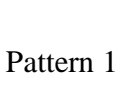

Fig. 2. Analysis of complementarity between the classifiers $A_{i}$ and $A_{j}$

\subsection{Analysis of the Complementarity between $A_{K+1}$ and $A_{i}, A_{j}$.}

When the new classifier $A_{K+1}$ is considered, two cases must be examined concerning respectively the minimum (Case (a)) and the maximum (Case (b)) value of the quantity (5): 
Case (a). In this case the outputs of $\mathrm{A}_{\mathrm{K}+1}$ must be as complementary as possible to those of $A_{i}$ and $A_{j}$. Hence, the recognitions of $A_{K+1}$ must occur according to the following priorities (see Fig. 3):

a.1) both $A_{i}$ and $A_{j}$ substitute the patterns (cases $A$ and $B$ ). For this case, the contribution of $\mathrm{A}_{\mathrm{K}+1}$ to the Similarity Index is null since $\mathrm{A}_{\mathrm{K}+1}$ disagrees both with $A_{i}$ and $A_{j}$. The percentage of patterns concerning (a.1) is $P_{A}+P_{B}$ at the best.

a.2) $A_{i}$ or $A_{i}$ substitute the patterns (cases $C$ and $E$ ). In this case $A_{K+1}$ agrees with $A_{i}$ or $A_{j}$. Therefore the contribution due to each pattern recognized by $A_{K+1}$ is weighted by 1 . The percentage of patterns concerning (a.2) is $P_{C}+P_{E}$ at the best.

a.3) both $A_{i}$ and $A_{j}$ recognise the patterns (case D). In this case $A_{K+1}$ agrees both with $A_{i}$ and $A_{j}$ Therefore the contribution due to each pattern recognized by $A_{K+1}$ is weighted by 2. The percentage of patterns concerning (a.3) is $\mathrm{P}_{\mathrm{D}_{2}}$ at the best, where $\mathrm{P}_{D_{2}}=R-\mathrm{P}_{\mathrm{A}}-\mathrm{P}_{\mathrm{B}}-\mathrm{P}_{\mathrm{C}}-\mathrm{P}_{\mathrm{E}}$ (if we assume the common condition: $\mathrm{R}>\mathrm{P}_{\mathrm{A}}-\mathrm{P}_{\mathrm{B}}-\mathrm{P}_{\mathrm{C}}-\mathrm{P}_{\mathrm{E}}$ ).

Concerning substitutions, it must be assumed that $\mathrm{A}_{\mathrm{K}+1}$ always provides substitutions as different as possible from those of $\mathrm{A}_{\mathrm{i}}$ and $\mathrm{A}_{\mathrm{j}}$. Hence it results (see figure 3):

$$
\rho_{\mathrm{A}_{\mathrm{i}}, \mathrm{A}_{\mathrm{K}+1}}+\rho_{\mathrm{A}_{\mathrm{j}}, \mathrm{A}_{\mathrm{K}+1}}=0 \cdot\left(\mathrm{P}_{\mathrm{A}}+\mathrm{P}_{\mathrm{B}}\right)+1 \cdot\left(\mathrm{P}_{\mathrm{C}}+\mathrm{P}_{\mathrm{E}}\right)+2 \cdot \mathrm{P}_{\mathrm{D}_{2}}=\mathrm{P}_{\mathrm{C}}+\mathrm{P}_{\mathrm{E}}+2 \cdot \mathrm{P}_{\mathrm{D}_{2}}
$$

where

$P_{c}$ is due to patterns recognised by $A_{K+1}$ and $A_{i}$, and substituted by $A_{i}$;

$\mathrm{P}_{\mathrm{D}_{2}}$ is due to patterns recognised by $\mathrm{A}_{\mathrm{K}+1}, \mathrm{~A}_{\mathrm{i}}$ and $\mathrm{A}_{\mathrm{j}}$;

$P_{E}$ is due to patterns recognised by $A_{K+1}$ and $A_{i}$, and substituted by and $A_{j}$.

Pattern 1

Pattern 2

Pattern 3

Pattern 4

Pattern 5

Pattern 6

Pattern 7

Pattern 8

Pattern 9

Pattern 10

\begin{tabular}{|c|c|c|c|}
\hline $\mathrm{A}_{\mathrm{i}}$ & $\mathrm{A}_{\mathrm{j}}$ & $\mathrm{A}_{\mathrm{K}+1}$ & \\
\hline S1 & $S 1$ & $R$ & $\mathbf{A}$ \\
\hline 52 & 53 & $\bar{R}$ & B \\
\hline S3 & $R$ & $R$ & C \\
\hline$R$ & $R$ & S1 & \multirow{3}{*}{$\mathbf{D}_{1}$} \\
\hline$R$ & $R$ & S2 & \\
\hline$R$ & $R$ & s3 & \\
\hline$R$ & $R$ & $R$ & \multirow{3}{*}{$\mathbf{D}_{2}$} \\
\hline$R$ & $R$ & $R$ & \\
\hline$R$ & $R$ & $R$ & \\
\hline$R$ & S2 & $R$ & $\mathbf{E}$ \\
\hline
\end{tabular}

Fig. 3. Analysis of complementarity among $A_{K+1}$ and $A_{i}, A_{j}$ - Case (a)

Substituting eqs. (9),(10),(11) and (12) in (13) it results:

$$
\rho_{\mathrm{A}_{\mathrm{i}}, \mathrm{A}_{\mathrm{K}+1}}+\rho_{\mathrm{A}_{\mathrm{j}}, \mathrm{A} \mathrm{K}+1}=2\left(\mathrm{R}-\left(\rho_{\mathrm{Ai}, \mathrm{Aj}}-\delta\right)\right)+2\left[\mathrm{R}-\delta-\left(1-2 \mathrm{R}+\rho_{\mathrm{Ai}, \mathrm{Aj}}-2 \delta\right)-2\left(\mathrm{R}-\left(\rho_{\mathrm{Ai}, \mathrm{Aj}}-\delta\right)\right)\right]=2(2 \mathrm{R}-1)
$$

Case (b). In this case the outputs of $A_{K+1}$ must be as similar as possible to those of $A_{i}$ and $\mathrm{A}_{\mathrm{i}}$. Hence, the recognitions of $\mathrm{A}_{\mathrm{K}+1}$ must occur according to the following priorities (see Fig. 4):

b.1) both $A_{i}$ and $A_{j}$ recognise the patterns (case D). For this case the contribution of $\mathrm{A}_{\mathrm{K}+1}$ to the Similarity Index is weighted by 2 , since $\mathrm{A}_{\mathrm{K}+1}$ agrees both with $\mathrm{A}_{\mathrm{i}}$ and $A_{i}$. The percentage of patterns concerning (b.1) is $P_{D}$ at the best. 
b.2) $A_{i}$ or $A_{i}$ substitute the patterns (cases $C$ and $E$ ). In this case $A_{K+1}$ agrees with $A_{i}$ or $A_{j}$. Therefore the contribution due to each pattern recognized by $A_{K+1}$ is weighted by 1 . The percentage of patterns concerning (b.2) is $\mathrm{P}_{\mathrm{C}}+\mathrm{P}_{\mathrm{E}}$ at the best.

b.3) both $A_{i}$ and $A_{j}$ substitute the patterns (cases $A$ and $B$ ). For these cases the contribution of $A_{K+1}$ to the Similarity Index is null since $A_{K+1}$ disagrees both with $A_{i}$ and $A_{j}$. The percentage of patterns concerning (b.1) is $P_{A}+P_{B}$ at the best.

Concerning substitutions, $\mathrm{A}_{\mathrm{K}+1}$ must provides substitutions as similar as possible to those of $\mathrm{A}_{\mathrm{i}}$ and $\mathrm{A}_{\mathrm{j}}$ Precisely:

b'.1) if $A_{i}(t)=A_{j}(t)=S i$ then it must results that $A_{K+1}(t)=S i$. For this case the contribution to the Similarity Index due to each pattern recognized by $\mathrm{A}_{\mathrm{K}+1}$ is weighted by 2 since $A_{K+1}$ agree both with $A_{i}$ and $A_{j}$. The percentage of patterns concerning ( $\left.b^{\prime} .1\right)$ is $\mathrm{P}_{\mathrm{A}}$ at the best.

$b^{\prime}$.2) if $A_{i}(t)=S i$ and $A_{j}(t)=S j$ then it must results that $A_{K+1}(t)=S i$ (or equivalently $\mathrm{A}_{\mathrm{K}+1}=\mathrm{Sj}$ ). For this case the contribution to the Similarity Index due to each pattern recognized by $A_{K+1}$ is weighted by 1 since $A_{K+1}$ agrees with $A_{i}\left(\right.$ or $\left.A_{j}\right)$. The percentage of patterns concerning ( $b^{\prime} .2$ ) is $\mathrm{P}_{\mathrm{B}}$ at the best (or equivalently $\mathrm{P}_{\mathrm{E}}$ ).

In this case we obtain (see figure 4):

$$
\rho_{A_{\mathrm{i}}, \mathrm{A}_{\mathrm{K}+1}}+\rho_{\mathrm{A}_{\mathrm{j}}, \mathrm{A}_{\mathrm{K}+1}}=2 \cdot \mathrm{P}_{\mathrm{D}}+1 \cdot\left(\mathrm{P}_{\mathrm{C}}+\mathrm{P}_{\mathrm{E}}\right)+2 \cdot \mathrm{P}_{\mathrm{A}}+1 \cdot \mathrm{P}_{\mathrm{B}}=2 \cdot \mathrm{P}_{\mathrm{A}}+\mathrm{P}_{\mathrm{B}}+\mathrm{P}_{\mathrm{C}}+2 \cdot \mathrm{P}_{\mathrm{D}}+\mathrm{P}_{\mathrm{E}}
$$

where:

- $\quad P_{A}$ is due to patterns substituted by $A_{K+1}, A_{i}$ and $A_{j}$ with the same class label;

- $\quad \mathrm{P}_{\mathrm{B}}$ is due to patterns substituted by $\mathrm{A}_{\mathrm{K}+1}$ and $\mathrm{A}_{\mathrm{i}}$ with the same class label, and by $\mathrm{A}_{\mathrm{j}}$ with a different class label;

- $\quad P_{C}$ is due to patterns recognised by $A_{K+1}$ and $A_{i}$, and substituted by $A_{j}$;

- $P_{D}$ is due to pattern recognised by $A_{K+1}, A_{i}$ and $A_{j}$;

- $\mathrm{P}_{\mathrm{E}}$ is due to pattern recognised by $\mathrm{A}_{\mathrm{K}+1}$ and $\mathrm{A}_{\mathrm{j}}$, and substituted by and $\mathrm{A}_{\mathrm{i}}$.

Pattern 1

Pattern 2

Pattern 3

Pattern 4

Pattern 5

Pattern 6

Pattern 7

Pattern 8

Pattern 9

Pattern 10

\begin{tabular}{|c|c|c|c|}
\hline $\mathrm{A}_{\mathrm{i}}$ & $\mathrm{A}_{\mathrm{j}}$ & $\mathrm{A}_{\mathrm{K}+}$ & \\
\hline S1 & S1 & S1 & A \\
\hline 52 & 53 & S2 & B \\
\hline S3 & $R$ & S3 & C \\
\hline$R$ & $R$ & $R$ & \\
\hline$R$ & $R$ & $R$ & \\
\hline$R$ & $R$ & $R$ & D \\
\hline$R$ & $R$ & $R$ & \\
\hline$R$ & $R$ & $R$ & \\
\hline$R$ & $R$ & $R$ & \\
\hline$R$ & 52 & $R$ & $\mathbf{E}$ \\
\hline
\end{tabular}

Fig. 4. Analysis of complementarity among $A_{K+1}$ and $A_{i}, A_{j}$ - Case (b)

Substituting eqs. (9),(10),(11) and (12) in (15) it results:

$$
\rho_{\mathrm{A}_{\mathrm{i}}, \mathrm{A}_{\mathrm{K}+1}}+\rho_{\mathrm{A}_{\mathrm{j}}, \mathrm{A}_{\mathrm{K}+1}}=2\left(\rho_{\mathrm{Ai}, \mathrm{Aj}}-\delta\right)+2 \delta+\left(\mathrm{R}-\left(\rho_{\mathrm{Ai}, \mathrm{Aj}}-\delta\right)\right)+\left(1-2 \mathrm{R}+\rho_{\mathrm{Ai}, \mathrm{Aj}}-2 \delta\right)=1+\rho_{\mathrm{Ai}, \mathrm{Aj}}
$$




\subsection{Analysis of the Complementarity of $\mathrm{A} \cup\left\{\mathrm{A}_{\mathrm{K}+1}\right\}$.}

From eqs. (14) and (16) it follows that, $\forall \mathrm{i}, \mathrm{j}=1,2, \ldots, \mathrm{N}$ :

$$
2(2 \mathrm{R}-1) \leq \rho_{\mathrm{A}_{\mathrm{i}}, \mathrm{A} K+1}+\rho_{\mathrm{A}_{\mathrm{j}}, \mathrm{A}_{\mathrm{K}+1}} \leq 1+\rho_{\mathrm{Ai}, \mathrm{Aj}} \text {. }
$$

Adding the inequalities (17), for $\mathrm{i}, \mathrm{j}=1,2, \ldots, \mathrm{N}, \mathrm{i}<\mathrm{j}$, it results:

$$
\begin{gathered}
\sum_{\substack{i, j=1 \\
i<j}}^{K} 2(2 R-1) \leq \sum_{\substack{i, j=1 \\
i<j}}^{K}\left(\rho_{A_{i}, A_{K}+1}+\rho_{A_{j}, A_{K}+1}\right) \leq \sum_{\substack{i, j=1 \\
i<j}}^{K}\left(1+\rho_{A_{i}, A_{j}}\right) \\
\left(\begin{array}{c}
K \\
2
\end{array}\right) 2(2 R-1) \leq(K-1) \sum_{i=1}^{K} \rho_{A_{i}, A_{K+1}} \leq\left(\begin{array}{c}
K \\
2
\end{array}\right)+\sum_{\substack{i, j=1 \\
i<j}}^{K} \rho_{A_{i}, A_{j}} \\
\left(\begin{array}{c}
K \\
2
\end{array}\right) 2(2 R-1) \leq(K-1) \sum_{i=1}^{K} \rho_{A_{i}, A_{K+1}} \leq\left(\begin{array}{c}
K \\
2
\end{array}\right)+\left(\begin{array}{c}
K \\
2
\end{array}\right) \rho_{A} \\
\frac{K(K-1)}{2} 2(2 R-1) \leq(K-1) \sum_{i=1}^{K} \rho_{A_{i}, A_{K}+1} \leq \frac{K(K-1)}{2}\left(1+\rho_{A}\right) \\
(2 R-1) K \leq \sum_{i=1}^{K} \rho_{A_{i}, A_{K+1}} \leq \frac{K}{2}\left(1+\rho_{A}\right)
\end{gathered}
$$

Substituting expression (18) in (4) we obtain that the range of variability of the Similarity Index, when a new classifier is added to the set A, is given by:

$$
\rho_{A \cup\left\{A_{K+1}\right\}} \in\left[\operatorname{Min} \rho_{A \cup\left\{A_{K+1}\right\}}, \operatorname{Max} \rho_{A \cup\left\{A_{K+1}\right\}}\right],
$$

where:

$$
\begin{aligned}
& \checkmark \quad \operatorname{Min} \rho_{A \cup\left\{A_{K+1}\right\}}=\frac{K-1}{K+1} \rho_{A}+\frac{2}{K(K+1)}(2 R-1) K=\frac{K-1}{K+1} \rho_{A}+2 \frac{2 R-1}{(K+1)} ; \\
& \checkmark \quad \operatorname{Max} \rho_{A \cup\left\{A_{K+1}\right\}}=\frac{K-1}{K+1} \rho_{A}+\frac{2}{K(K+1)} \frac{K}{2}\left(1+\rho_{A}\right)=\frac{K}{K+1} \rho_{A}+\frac{1}{(K+1)} .
\end{aligned}
$$

\section{Analysis of Combination Methods}

Although classifier combination is widely applied in many fields, theoretical analysis of combination schemes can be very difficult. The net result is that only simple combination have been explained up to now from a theoretical point of view [8]. In many cases the performance of a combination method cannot be estimated theoretically and it can be evaluated on experimental basis in specific working conditions (a specific set of classifiers, training data and sessions, etc.). In this case the result depends on the specific conditions of the test and no information can be derived on the performance of the combination method if the working conditions change. A different approach to estimate systematically the performance of a combination method $\mathbf{C}$ for abstract-level classifiers is based on the simulation of various sets of classifiers which are used to test the method under different conditions 
[9]. In this case, performance of $\mathbf{C}$, which combines $\mathrm{K}$ abstract-level classifiers, is evaluated as a function of the recognition rate of the classifiers $(\mathrm{R})$ and the degree of complementarity among them $(\rho)$ :

$$
\mathbf{C}(K, R, \rho) \rightarrow\left(R_{\mathbf{C}}, L_{\mathbf{C}}\right)
$$

where $R_{\mathbf{C}}$ and $L_{\mathbf{C}}$ are respectively the recognition rate and the reliability rate of $\mathbf{C}$ [1]. More precisely, since abstract-level classifiers are combined, each individual classifier is considered as a discrete random variable whose outputs are $\mathrm{N}$ class labels if $\mathrm{N}$ patterns are supposed to be input: $\mathrm{N} \cdot \mathrm{R}$ recognitions (labels equal to R) and $\mathrm{N} \cdot(1-$ $R$ ) substitutions (labels equal to $S 1, S 2, S 3, \ldots)$. Of course, for any 3 -tuple $(K, R, \rho)$, several sets (50 in out tests) of classifiers are simulated and used to test the combination method $\mathbf{C}$, in order to estimate its mean performance in terms of $\mathbf{R}_{C}$ and $\mathrm{L}_{\mathrm{C}}$.

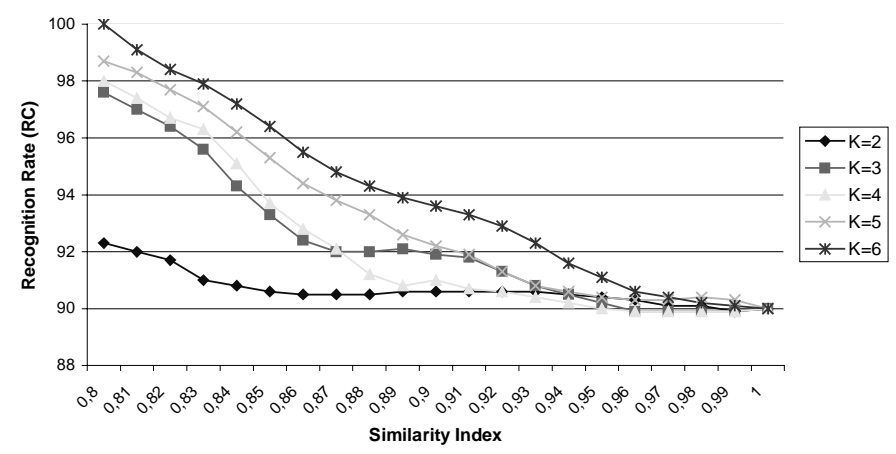

(a)

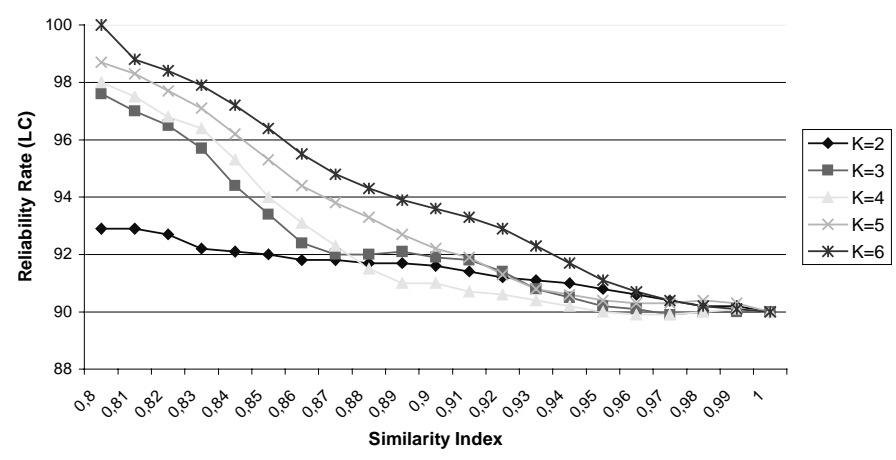

(b)

Fig. 5. Performance of DS as a function of $\rho$ in combining K classifiers ( $R=90 \%)$

In this work, the behaviour of the Dempster-Shafer (DS) combination method is analysed [10]. Specifically, we use the DS combination scheme and the decision rule proposed respectively in Section VI.C and Section VI.D (eq. [50], $\alpha=0$ ) of ref. [1]. The performance of DS is reported in Figure 5 as a function of $\rho$, when sets of $K$ 
classifiers are combined $(\mathrm{K}=2,3,4,5,6)$, each one with a recognition rate equal to $\mathrm{R}=90 \%$ (see ref. [11] for more details).

\section{Experimental Results}

This Section shows the analysis of complementarity of a set of classifiers, as the number of classifiers increases. Based on this result, the performance of the Dempster-Shafer (DS) method in combining classifiers is investigated. Two cases are discussed hereafter.

Case (a). In this case four initial sets of classifiers $A=\left\{A_{i} \mid i=1,2, \ldots, K\right\}$, for $\mathrm{K}=2,3,4,5$, are given. The recognition rate of the classifiers is $\mathrm{R}=90 \%$ and the degree of complementarity of each set is $\rho_{\mathrm{A}}=0.85$.

Table 1. DS Performance as the number of classifier increases: Case (a)

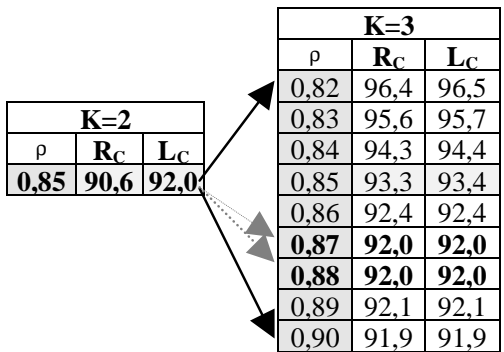

(a) $2 \rightarrow 3$

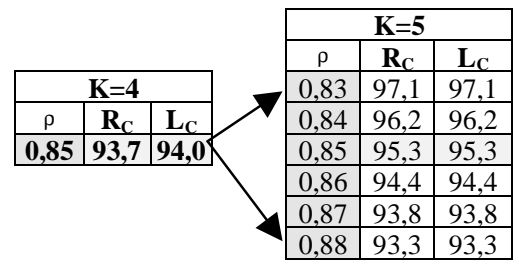

(c) $4 \rightarrow 5$

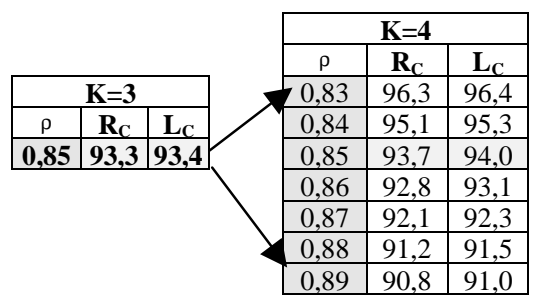

(b) $3 \rightarrow 4$

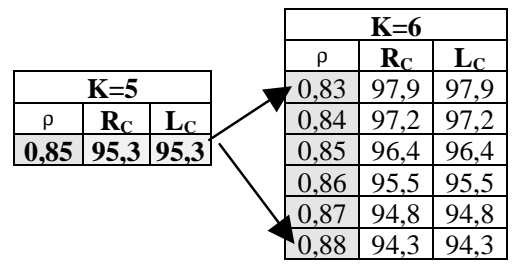

(d) $5 \rightarrow 6$

Table 1 reports the effect of adding one extra classifier to each set. Eqs. (19) and (20) are used to determine the range of variability of the degree of complementarity, while the results in Fig.5 allows the prediction of the performance of the DS method:

* for $K=2$ (Table 1a), DS performance is equal to $\mathbf{R}_{C}=90.6, \mathbf{L}_{C}=92.0$ (Fig. 5). If an extra classifier $A_{K+1}$ is added to $A$, the complementarity of $A \cup\left\{A_{K+1}\right\}$ is in the range $[0.82,0.90]$ (eqs.(19),(20)). Hence it results that the expected performance for $A \cup\left\{A_{K+1}\right\}$ ranges from $\mathbf{R}_{C}=91.9, \mathbf{L}_{C}=91.9$ (Fig.5, for $\rho_{A} \cup_{\left\{A_{K+1}\right\}}=0.90$ ) to $\mathbf{R}_{C}=$ 96.4, $\mathbf{L}_{\mathrm{C}}=96.5$ (Fig.5, for $\rho_{\mathrm{A} \cup\left\{\mathrm{A}_{\mathrm{K}+1}\right\}}=0.82$ ).

* for $K=3$ (Table 1b), DS performance is equal to $\mathbf{R}_{C}=93.3, \mathbf{L}_{C}=93.4$ (Fig. 5). If an extra classifier $A_{K+1}$ is added to $A$, the complementarity of $A \cup\left\{A_{K+1}\right\}$ is in the range [0.83, 0.89] (eqs.(19),(20)) and from Fig. 5 it results that the expected 
performance for $A \cup\left\{A_{K+1}\right\}$ ranges from $\mathbf{R}_{C}=90.8, \quad \mathbf{L}_{C}=91.0$ (Fig. 5, for $\rho_{\mathrm{A} \cup\left\{\mathrm{A}_{\mathrm{K}+1}\right\}}=0.89$ ) to $\mathbf{R}_{\mathrm{C}}=96.3, \mathbf{L}_{\mathrm{C}}=96.4$ (Fig. 5, for $\rho_{\mathrm{A} \cup\left\{\mathrm{A}_{\mathrm{K}+1}\right\}}=0.83$ ).

Similar considerations lead to the results in Table 1c,d.

Case (b). In this case the initial set of $K=2$ classifiers $A=\left\{A_{1}, A_{2}\right\}$ is given, with $R=90 \%$ and $\rho_{A}=0.85$, and four extra classifiers $A_{3}, A_{4}, A_{5}$ and $A_{6}$ are added to the set A, one after the other (es. $2 \rightarrow 3 \rightarrow 4 \rightarrow 5 \rightarrow 6$ ). In this case eqs (19) and (20) must be applied by an iterative scheme, in order to predict the range of variability of the enlarged sets of classifiers:

* when $A_{3}$ is added to the set $A$, the degree of complementarity $\rho_{A \cup\{A\}}$ can varies in the range $\rho_{\mathrm{A} \cup\{\mathrm{A}\}} \in[0.82,0.90]$ (eqs. (19), (20)) and from Fig.5 the performance of DS ranges from $\mathbf{R}_{\mathrm{C}}=91.9, \mathbf{L}_{\mathrm{C}}=91.9$ (for $\rho_{\left.\mathrm{A} \cup \mathrm{A}_{\mathrm{K}+1}\right]}=0.90$ ) to $\mathbf{R}_{\mathrm{C}}=96.4, \mathbf{L}_{\mathrm{C}}=96.5$ (for $\left.\rho_{\mathrm{A} \cup\left\{\mathrm{A}_{\mathrm{K}+1}\right\}}=0.82\right)$.

* when $A_{4}$ is added to $A \cup\left\{A_{3}\right\}$, the degree of complementarity of the set $A \cup\left\{A_{3}\right\}$ $\cup\left\{A_{4}\right\}$ can varies in the range $\rho_{A} \cup_{\{A 3\}} \cup_{\{A 4\}} \in[0.81,0.93]$ (where, of course, the lower bound of $\rho_{A \cup\{A 3\}} \cup_{\{A 4\}}$ is obtained by applying eq. (19) to the lower bound of $\rho_{\mathrm{A} \cup\{\mathrm{A}\}}$, and the upper bound of $\rho_{\mathrm{A} \cup\{\mathrm{A}\}} \cup_{\{\mathrm{A}\}}$ is obtained by applying eq. (20) to the upper bound of $\left.\rho_{A \cup\{A\}}\right)$. For the set $A \cup\left\{A_{3}\right\} \cup\left\{A_{4}\right\}$, Fig. 5 shows that the expected performance of DS ranges from $\mathbf{R}_{C}=90.4, \mathbf{L}_{C}=90.4$ (for $\rho_{A} \cup_{\{A\}\}} \cup_{\{A 4\}}=0.93$ ) to $\mathbf{R}_{\mathrm{C}}=97.4, \mathbf{L}_{\mathrm{C}}=97.5$ (for $\rho_{\mathrm{A} \cup\{\mathrm{A}\}\}} \cup_{\{\mathrm{A} 4\}}=0.82$ ).

This procedure is bring to the end, in order to obtain the results in Table 2.

Table 2. DS Performance as the number of classifier increases: Case (b).

\begin{tabular}{|c|c|c|c|c|c|c|c|c|c|c|c|c|c|c|}
\hline & & & & & & & & & & \multicolumn{3}{|c|}{$\begin{array}{c}\mathbf{K}=\mathbf{6} \\
\left(\mathrm{A} \cup \mathrm{A}_{3} \cup \mathrm{A}_{4} \cup \mathrm{A}_{5} \cup \mathrm{A}_{6}\right)\end{array}$} \\
\hline & & & & & & \multicolumn{3}{|c|}{$\begin{array}{c}\mathbf{K}=\mathbf{4} \\
\left(\mathrm{A} \cup \mathrm{A}_{3} \cup \mathrm{A}_{4}\right)\end{array}$} & \multicolumn{3}{|c|}{$\begin{array}{c}\mathbf{K}=\mathbf{5} \\
\left(\mathrm{A} \cup \mathrm{A}_{3} \cup \mathrm{A}_{4} \cup \mathrm{A}_{5}\right)\end{array}$} & $\rho$ & $\mathbf{R}_{\mathrm{C}}$ & $\mathbf{L}_{\mathbf{C}}$ \\
\hline & & & \multicolumn{3}{|c|}{$\mathbf{K}=\mathbf{3}\left(\mathrm{A} \cup \mathrm{A}_{3}\right)$} & $\rho$ & $\mathbf{R}_{\mathrm{C}}$ & $\mathbf{L}_{\mathbf{C}}$ & $\rho$ & $\mathbf{R}_{\mathrm{C}}$ & $\mathbf{L}_{\mathrm{C}}$ & 0,80 & 100 & 100 \\
\hline & & & $\rho$ & $\mathbf{R}_{\mathrm{C}}$ & $\mathbf{L}_{\mathrm{C}}$ & 0,81 & 97,4 & 97,5 & 0,81 & 98,3 & 98,3 & 0,81 & 99,1 & 99,1 \\
\hline & & & 0,82 & 96 & 96,5 & 0,82 & 96,7 & 96,8 & 0,82 & 97,7 & 97,7 & 0,82 & 98,4 & 98,4 \\
\hline \multicolumn{3}{|c|}{$\mathbf{K}=\mathbf{2}\left(\mathrm{A}=\left\{\mathrm{A}_{1}, \mathrm{~A}_{2}\right\}\right)$} & 0,83 & 95,6 & 95,7 & 0,83 & 96,3 & 96,4 & 0,83 & 97,1 & 97,1 & 0,83 & 97,9 & 97,9 \\
\hline$\rho$ & $\mathbf{R}_{\mathrm{C}}$ & $\mathbf{L}_{\mathrm{C}}$ & 0,84 & 94,3 & 94,4 & 0,84 & 95,1 & 95,3 & 0,84 & 96,2 & 96,2 & 0,84 & 97,2 & 97,2 \\
\hline \multirow[t]{11}{*}{0,85} & 90,6 & 92,0 & 0,85 & 93,3 & 93,4 & 0,85 & 93,7 & 94,0 & 0,85 & 95,3 & 95,3 & 0,85 & 96,4 & 96,4 \\
\hline & & & 0,86 & 92,4 & 92,4 & 0,86 & 92,8 & 93,1 & 0,86 & 94,4 & 94,4 & 0,86 & 95,5 & 95,5 \\
\hline & & & 0,87 & 92,0 & 92,0 & 0,87 & 92,1 & 92,3 & 0,87 & 93,8 & 93,8 & 0,87 & 94,8 & 94,8 \\
\hline & & & 0,88 & 92,0 & 92,0 & 0,88 & 91,2 & 91,5 & 0,88 & 93,3 & 93,3 & 0,88 & 94,3 & 94,3 \\
\hline & & & 0,89 & 92,1 & 92,1 & 0,89 & 90,8 & 91,0 & $\mathbf{0 , 8 9}$ & 92,6 & 92,7 & 0,89 & 93,9 & 93,9 \\
\hline & & & 0,90 & 91,9 & 91,9 & 0,90 & 91,0 & 91,0 & 0,90 & 92,2 & 92,2 & 0,90 & 93,6 & 93,6 \\
\hline & & & & & & 0,91 & 90,7 & 90,7 & 0,91 & 91,9 & 91,9 & 0,91 & 93,3 & 93,3 \\
\hline & & & & & & 0,92 & 90,6 & 90,6 & 0,92 & 91,3 & 91,3 & 0,92 & 92,9 & 92,9 \\
\hline & & & & & & 0,93 & 90,4 & 90,4 & 0,93 & 90,8 & 90,8 & 0,93 & 92,3 & 92,3 \\
\hline & & & & & & & & & 0,94 & 90,6 & 90,6 & 0,94 & 91,6 & 91,7 \\
\hline & & & & & & & & & & & & 0,95 & 91,1 & 91,1 \\
\hline
\end{tabular}

Finally, a multi-classifier system for hand-written numeral recognition has been considered. The system combines by DS up to six classifiers trained on 12.000 digits extracted from courtesy amounts on bank-checks [12]: $\mathbf{A}_{1}$-Region, $\mathbf{A}_{2}$-Crossing, $\mathbf{A}_{3}$ Contour Slope, $\mathbf{A}_{4}$-Enhanced Loci, $\mathbf{A}_{5}$-Histogram, $\mathbf{A}_{6}$-Local Contour. Each classifiers outputs a single class label and no rejection is allowed at the level of individual 
classifiers. Moreover the recognition rate of each classifier is about $90 \%$ (differences are less than $0.4 \%)$. Table 3 reports the values of $\rho$ for each subset $(K=2,3,4,5,6)$ of classifiers. It is easy to verify from Tables 1 and 2 that the complementarity measured on real sets of classifiers, as the number of classifiers increases, is consistent with the results determined in eqs. (19), (20) (for instance, the particular case of adding new classifiers to the set $\left\{\mathrm{A}_{4}, \mathrm{~A}_{6}\right\}$, for which $\rho_{\mathrm{A}}=0.85$, is reported in bold type in Table 3 and in Tables 1,2). Finally, the effect of increasing the number of classifier on the performance of the multi-classifier system has been evaluated. It results that the differences between predicted and real recognition rate is less than $1.0 \%$, while it is less than $1.3 \%$ in terms of reliability rate.

Table 3. Degree of Complementarity of sets of classifiers

\begin{tabular}{|c|c|c|c|c|c|c|c|c|c|}
\hline \multicolumn{2}{|c|}{$K=2$} & \multicolumn{2}{|c|}{$K=3$} & \multicolumn{2}{|c|}{$K=4$} & \multicolumn{2}{|l|}{$K=5$} & \multicolumn{2}{|l|}{$K=6$} \\
\hline $\mathbf{A}$ & $\rho_{\mathrm{A}}$ & $\mathbf{A}$ & $\rho_{A}$ & $\mathbf{A}$ & $\rho_{A}$ & A & $\rho_{A}$ & $\mathbf{A}$ & $\rho_{A}$ \\
\hline $\mathbf{A}_{4}, \mathbf{A}_{6}$ & $\mathbf{0 , 8 5}$ & $\mathrm{A}_{1}, \mathrm{~A}_{2}, \mathrm{~A}_{6}$ & 0,87 & $\mathbf{A}_{2}, \mathbf{A}_{3}, \mathbf{A}_{4}, \mathbf{A}_{6}$ & 0,87 & $\mathbf{A}_{1}, \mathbf{A}_{2}, \mathbf{A}_{3}, \mathbf{A}_{4}, \mathbf{A}_{6}$ & $\mathbf{0 , 8 8}$ & $\mathbf{A}_{1}, \mathbf{A}_{2}, \mathbf{A}_{3}, \mathbf{A}_{4}, \mathbf{A}_{5}, \mathbf{A}_{6}$ & 0,89 \\
\hline $\mathrm{A}_{1}, \mathrm{~A}_{6}$ & 0,86 & $\mathrm{~A}_{2}, \mathrm{~A}_{3}, \mathrm{~A}_{6}$ & 0,87 & $\mathbf{A}_{1}, \mathbf{A}_{2}, \mathbf{A}_{4}, \mathbf{A}_{6}$ & $\mathbf{0 , 8 8}$ & $\mathrm{A}_{1}, \mathrm{~A}_{2}, \mathrm{~A}_{3}, \mathrm{~A}_{5}, \mathrm{~A}_{6}$ & 0,89 & & \\
\hline $\mathrm{A}_{2}, \mathrm{~A}_{6}$ & 0,87 & $\mathbf{A}_{3}, \mathbf{A}_{4}, \mathbf{A}_{6}$ & 0,87 & $\mathbf{A}_{1}, \mathbf{A}_{3}, \mathbf{A}_{4}, \mathbf{A}_{6}$ & $\mathbf{0 , 8 8}$ & $\mathbf{A}_{1}, \mathbf{A}_{2}, \mathbf{A}_{4}, \mathbf{A}_{5}, \mathbf{A}_{6}$ & $\mathbf{0 , 8 9}$ & & \\
\hline $\mathrm{A}_{3}, \mathrm{~A}_{6}$ & 0,87 & $\mathbf{A}_{2}, \mathbf{A}_{4}, \mathbf{A}_{6}$ & 0,87 & $\mathbf{A}_{2}, \mathbf{A}_{4}, \mathbf{A}_{5}, \mathbf{A}_{6}$ & $\mathbf{0 , 8 8}$ & $\mathbf{A}_{1}, \mathbf{A}_{3}, \mathbf{A}_{4}, \mathbf{A}_{5}, \mathbf{A}_{6}$ & 0,89 & & \\
\hline $\mathrm{A}_{1}, \mathrm{~A}_{2}$ & 0,88 & $\mathrm{~A}_{2}, \mathrm{~A}_{3}, \mathrm{~A}_{4}$ & 0,88 & $\mathrm{~A}_{1}, \mathrm{~A}_{2}, \mathrm{~A}_{3}, \mathrm{~A}_{4}$ & 0,89 & $A_{2}, A_{3}, A_{4}, A_{5}, A_{6}$ & $\mathbf{0 , 8 9}$ & & \\
\hline $\mathrm{A}_{2}, \mathrm{~A}_{3}$ & 0,88 & $A_{4}, A_{5}, A_{6}$ & $\mathbf{0 , 8 8}$ & $\mathrm{A}_{1}, \mathrm{~A}_{2}, \mathrm{~A}_{3}, \mathrm{~A}_{6}$ & 0,89 & $\mathrm{~A}_{1}, \mathrm{~A}_{2}, \mathrm{~A}_{3}, \mathrm{~A}_{4}, \mathrm{~A}_{5}$ & 0,90 & & \\
\hline $\mathrm{A}_{2}, \mathrm{~A}_{4}$ & 0,88 & $\mathrm{~A}_{1}, \mathrm{~A}_{3}, \mathrm{~A}_{6}$ & 0,88 & $\mathrm{~A}_{1}, \mathrm{~A}_{2}, \mathrm{~A}_{5}, \mathrm{~A}_{6}$ & 0,89 & & & & \\
\hline $\mathrm{A}_{5}, \mathrm{~A}_{6}$ & 0,88 & $\mathbf{A}_{1}, \mathbf{A}_{4}, \mathbf{A}_{6}$ & $\mathbf{0 , 8 8}$ & $\mathrm{A}_{1}, \mathrm{~A}_{3}, \mathrm{~A}_{5}, \mathrm{~A}_{6}$ & 0,89 & & & & \\
\hline $\mathrm{A}_{3}, \mathrm{~A}_{4}$ & 0,89 & $\mathrm{~A}_{1}, \mathrm{~A}_{5}, \mathrm{~A}_{6}$ & 0,88 & $\mathbf{A}_{1}, \mathbf{A}_{4}, \mathbf{A}_{5}, \mathbf{A}_{6}$ & 0,89 & & & & \\
\hline $\mathrm{A}_{1}, \mathrm{~A}_{3}$ & 0,90 & $\mathrm{~A}_{1}, \mathrm{~A}_{2}, \mathrm{~A}_{3}$ & 0,89 & $\mathrm{~A}_{2}, \mathrm{~A}_{3}, \mathrm{~A}_{5}, \mathrm{~A}_{6}$ & 0,89 & & & & \\
\hline $\mathrm{A}_{4}, \mathrm{~A}_{5}$ & 0,90 & $\mathrm{~A}_{1}, \mathrm{~A}_{2}, \mathrm{~A}_{4}$ & 0,89 & $\mathbf{A}_{3}, \mathbf{A}_{4}, \mathbf{A}_{5}, \mathbf{A}_{6}$ & 0,89 & & & & \\
\hline $\mathrm{A}_{1}, \mathrm{~A}_{5}$ & 0,91 & $\mathrm{~A}_{2}, \mathrm{~A}_{5}, \mathrm{~A}_{6}$ & 0,89 & $\mathrm{~A}_{1}, \mathrm{~A}_{2}, \mathrm{~A}_{4}, \mathrm{~A}_{5}$ & 0,90 & & & & \\
\hline $\mathrm{A}_{1}, \mathrm{~A}_{4}$ & 0,92 & $\mathrm{~A}_{1}, \mathrm{~A}_{3}, \mathrm{~A}_{4}$ & 0,90 & $\mathrm{~A}_{2}, \mathrm{~A}_{3}, \mathrm{~A}_{4}, \mathrm{~A}_{5}$ & 0,90 & & & & \\
\hline $\mathrm{A}_{2}, \mathrm{~A}_{5}$ & 0,92 & $\mathrm{~A}_{2}, \mathrm{~A}_{4}, \mathrm{~A}_{5}$ & 0,90 & $\mathrm{~A}_{1}, \mathrm{~A}_{2}, \mathrm{~A}_{3}, \mathrm{~A}_{5}$ & 0,91 & & & & \\
\hline$A_{3}, A_{5}$ & 0,95 & $\mathrm{~A}_{3}, \mathrm{~A}_{5}, \mathrm{~A}_{6}$ & 0,90 & $\mathrm{~A}_{1}, \mathrm{~A}_{3}, \mathrm{~A}_{4}, \mathrm{~A}_{5}$ & 0,91 & & & & \\
\hline & & $\mathrm{A}_{1}, \mathrm{~A}_{2}, \mathrm{~A}_{5}$ & 0,91 & & & & & & \\
\hline & & $\mathrm{A}_{2}, \mathrm{~A}_{3}, \mathrm{~A}_{5}$ & 0,91 & & & & & & \\
\hline & & $\mathrm{A}_{3}, \mathrm{~A}_{4}, \mathrm{~A}_{5}$ & 0,91 & & & & & & \\
\hline & & $\mathrm{A}_{1}, \mathrm{~A}_{4}, \mathrm{~A}_{5}$ & 0,91 & & & & & & \\
\hline & & $\mathrm{A}_{1}, \mathrm{~A}_{3}, \mathrm{~A}_{5}$ & 0,92 & & & & & & \\
\hline
\end{tabular}

\section{Conclusion}

This paper presents a complementarity-based analysis of sets of abstract-level classifiers and uses the results to investigate the performance of multi-classifier systems, as the number of classifiers increases. This work clarifies important aspects of the collective behaviour of multiple classifiers systems, based on the analysis of complementarity among them.

Acknowledgements. This paper has been supported by the Italian Ministry "Ministero dell'Istruzione, dell'Università e della Ricerca ", MIUR under law 488, Project "Rete Puglia" CINI-BA - D.M. n.600, 11-11-1999.

\section{References}

1. Ley Xu, Adam Krzyzak, Ching Y-Suen, "Methods of Combining Multiple Classifiers and Their Applications to Handwriting Recognition", IEEE Transaction on Systems, Man and Cybernetics, Vol. 22, N. 3, 1992, pp. 418-435. 
2. L. Lam, Y.-S. Huang, C.Y. Suen, "Combination of Multiple Classifier Decision for Optical Character Recognition", in Handbook of Character Recognition and Document Image Analysis, Eds. H. Bunke and P.S.P.Wang, World Scient. Publ., Singapore,1997,pp.79-101.

3. D. Wolpert, "Stacked Generalization", Neural Networks, Vol. 5, pp. 241-259, 1992.

4. T.K.Ho, "Random Decision Forests", Proc.ICDAR '95,Montreal,Canada,1995, pp.278282.

5. L. Breiman, "Bagging Predictors", Machine Learning, Vol. 24, no. 2, pp. 123-140, 1996.

6. R.E.Schapire, "The strength of weak Learnability", Mach. Learning,Vol.5,pp.197-227, 1990.

7. G. Dimauro, S. Impedovo, G. Pirlo, A. Salzo, "Multiple Classifiers: a new methodology for the evaluation of the combination processes", Progress in Handwriting Recognition, A.C.Downton and S. Impedovo (eds.), World Scientific, Singapore, pp. 329-335, 1995.

8. J. Kittler, M. Hatef, R.P.W. Duin and J. Matias, "On combining classifiers", IEEE TPAMI, vol. 20, no. 3, pp. 226-239, 1998.

9. V.Di Lecce, G.Dimauro, A.Guerriero, S.Impedovo, G.Pirlo, A.Salzo, "Classifier Combination: The role of a-priori knowledge", IWFHR VII, eds. L.R.B. Schomaker et al., 2000, Nijmegen: International Unipen Foundation Publishing, pp. 143-152.

10. E. Mandler and J. Schuermann, "Combining the Classification Results of independent classifiers based on the Dempster/Shafer theory of evidence", in Pattern Recognition and Artificial Intelligence, eds. E.S.Gelsema et al., North Holland,Amsterdam,1988,pp.381393.

11. S. Impedovo and A. Salzo, "A new methodology for expert combination in multi-expert system designing". In Lecture Notes in Computer Science, (vol. 1857), J. Kittler and F.Roli Eds., MCS2000, Cagliari, Italy, pp.230-239.

12. G.Dimauro, S.Impedovo, G.Pirlo, A.Salzo, "Automatic Bankchecks Processing: A New Engineered System”, Int. Journal of Pattern Recognition and Artificial Intelligence, Vol.11, N.4, World Scientific Publ.,Singapore, 1997, pp.1-38. 